\title{
Uma anotaÇão à Clínica: Gilles Deleuze, ESQUIZOFRENIA E SUA POSITIVIDADE
}

\author{
Maria Elizabeth Barros $\star$ \\ Juan Carlos Peixoto Pereira ${ }^{\star}$
}

\begin{abstract}
Resumo
$O$ artigo trata a questão da esquizofrenia, tomada como um signo negativo quando se instala como patologia no campo das psicoses. Afirma que o discurso médico psiquiátrico celebrou seu advento e comemorou tais possibilidades que o pensamento "freudo-bleuleriano" abriu e desvelou. Considera que a carreira da esquizofrenia, atravessando o movimento político da antipsiquiatria, confrontou-se com outra sorte de experiências, sendo registrada segundo uma nova lógica que, sob as condições impostas pelo acontecimento freudiano, transformou o saber no século XX. Afirma que Gilles Deleuze compreendeu esse aturdimento, recolheu a parte que lhe cabia e documentou-a, em particular em sua obra Lógica do Sentido quando inverteu a polaridade dos signos, positivando a esquizofrenia.
\end{abstract}

Palavras-chave: esquizofrenia; Deleuze; clínica.

\section{An annotation to Clinic: Gilles Deleuze,}

\section{SCHIZOPHRENIA AND ITS POSITIVITY}

\begin{abstract}
The article discuss about the subject of schizophrenia, taken as a negative sign when it's taken as pathology in the field of psychoses. It affirms that the medical psychiatric discourse celebrated its advent and commemorated such possibilities opened and revealed by the "freud-bleulerian" thought. It considers that the career of the schizophrenia, crossing the Anti-Psychiatry political movement, was confronted with another sort of experiences, being registered under a new logic that, under the conditions imposed by the Freudian happening, transformed the twentieth century's knowledge. It affirms that Gilles Deleuze understood that stunning, collected the part that fit him and documented it, especially in his work The Logic of Sense when inverted the polarity of the signs, making schizophrenia positive.
\end{abstract}

Keywords: schizophrenia; Deleuze; clinic.

\footnotetext{
^ Psicóloga. Mestrado em Psicologia Escolar pela Universidade Gama Filho, doutorado em Educação pela Universidade Federal do Rio de Janeiro e pós -doutorado em saúde pública pela ENSP/ Fiocruz. Atualmente é professora titular da Universidade Federal do Espírito Santo. Endereço: Universidade Federal do Espírito Santo, Centro de Ciências Humanas e Naturais, Departamento de Psicologia. Av. Fernando Ferrari, s/n.Goiabeiras. - Vitoria, ES - Brasil. CEP : 29060900. E-mail: betebarros@uol.com.br

$\star \star$ Psicólogo. Especialização em Filosofia pela Universidade Federal de Minas Gerais. Professor do Departamento de Psicologia da Universidade Federal do Espírito Santo.

E-mail: jpaperbz@hotmail.com
} 


\section{Onde se desenha um contexto Epistemológico, Crítico e Clínico sui generis}

Consideremos, durante um instante por "fingimento", que não sabemos quem é o autor deste texto:

Como regra geral a análise psicossocial das famílias de esquizofrênicos só pode ser conduzida pela intermediação das regras formais instauradas pelo pensamento esquizofrênico, e não o inverso. $\mathrm{O}$ estudo dessas regras formais não é certamente favorecido pelos antigos-lugares comuns sobre o pensamento pré-lógico, a participação, a identificação, a dissociação, os mecanismos do sonho: ao contrário. O estudo do formalismo esquizofrênico, e do "não-sentido" onde ele se desdobra por si mesmo e positivamente, encontrou já um certo desenvolvimento nos trabalhos de G. Bateson e sua escola cf. Toward a theory of schizophrenia [Para uma teoria da esquizofrenia], Behavioral Science, 1966 [e o relatório que dele fez Pierre Fédida, Psychose et Parenté, Critique, octobre 1968]. É certo que a teoria lacaniana, relativa à posição do esquizofrênico na ordem simbólica, é suscetível de dar a essa pesquisa novas bases (DELEUZE, 1970, p. 11).

Sob todos os aspectos trata-se de uma observação com alto grau de elaboração teórica, acuidade técnica e aguda crítica epistemológica. Tal crítica incide de forma contundente nos pressupostos filosóficos do racionalismo e iluminismo, baseado no pensamento absolutista da subjetividade que imperou do século XVII ao XIX, cujo golpe foi dado por Freud, Nietzsche, Marx, dentre outros. O cogito cartesiano e kantiano foi destronado em nome de uma subjetividade cindida, uma inessencialidade do sujeito, por exemplo.

Daí se atribuir ao pensamento pré-lógico a participação, a identificação, a dissociação, os mecanismos do sonho - a qualificação de "clichês" - destitui-se e desautoriza-se boa parte de ideias e práticas relativas à questão da "psicose esquizofrênica", em favor de uma iniciativa que se quer nova - estampada com todas as letras nessa nota, posto que se possa depreender que, doravante o pensamento esquizofrênico comporta um elemento de positividade.

Ademais, nos parece, a partir de Deleuze (1970), ter sido assegurado que o deslocamento de eixos do campo das "neuroses" para a psicose inicia uma nova "torção". Com este último termo nos vemos confrontados com uma dimensão que se nos impõe: a da "clínica". O que acima se lê é uma observação clínica. Clínica das psicoses pensada a partir do cogito "esquizo" . Trata-se, então, de um cogito que implica apreender um novo modo de pensar pautado num pensamento rizomático (em rede) marcado pelos princípios da heterogeneidade (antiestruturalista), da multiplicidade, da ruptura a-significante e da cartografia. Trata-se, portanto, de um pensamento a-centrado, não hierárquico, constituído de platôs sem início e sem fim. 


\section{DeCisÃo do FILÓSOFO, CLÍNICA DA ESQUIZOFRENIA}

A noção de loucura - no nome esquizofrenia - deverá vir a ser solidária com a linguagem que, por sua vez, relacionar-se-á com o saber. Esse reconhecimento essa solidariedade - deve-se à história da filosofia, lá, na aurora do pensamento.

A astuciosa sugestão deleuziana concerne à leitura de Platão. É que, após a admissão do dualismo de Platão (Ideia e Matéria), é necessário continuar. Todavia, a dualidade admitida é outra "[...] mais profunda, mais secreta, oculta nos próprios corpos sensíveis e materiais: dualidade subterrânea entre o que recebe a ação da Ideia e o que se subtrai a esta ação" (DELEUZE, 1998, p. 2). Se assim é, algo sempre pode ser revelado, desvelado. Há alguma coisa que se encontra por debaixo. Algo clandestino, oculto.

Esse algo, para Deleuze (1998) não é, simplesmente, a distinção do Modelo e da cópia, mas das cópias e simulacros, uma vez que esse trabalho já foi feito pela "divisão", seleção e "exclusão", do método platônico.

No Platão deleuziano duas dimensões são apontadas: a das coisas limitadas e medidas e de qualidades fixas, permanentes ou temporárias e um puro devir sem medida, o que Deleuze (1998, p. 2) vai chamar de um verdadeiro devir-louco que não se detêm nunca, "nos dois sentidos ao mesmo tempo, sempre se furtando ao presente, fazendo coincidir o futuro e o passado".

$\mathrm{O}$ que disso podemos compreender? O que da astúcia do historiador de filosofia podemos acompanhar?

Da leitura crítica de um pensamento distanciado mais de dois milênios em nossa cronologia trivial - pensamento milenar que insiste e subsiste nesse lapso temporal vazado pelo próprio signo que define essa duração, quer dizer, A.C. e D.C -, dessa leitura surge, cintila, o que se segue: "o puro devir, o ilimitado, é a matéria do simulacro" (DELEUZE, 1998, p. 2), o que nos indica muito exatamente o "fora excluído" pelo método de "divisão" - platônica, na medida em que nesse movimento se furta à Ação da Ideia, uma vez que contesta ao mesmo tempo tanto o "modelo" como a cópia, da qual conviria, para o filósofo, a suspeição de que sob as Ideias temos as coisas medidas e sob as próprias coisas não haveria ainda este "elemento louco que subsiste, que 'sub-vem', aquém da ordem imposta pelas Idéias e recebida pela coisa?” (DELEUZE, 1998, p. 2).

É do próprio texto platônico que caberia então perguntar se este "puro devir" não estaria numa relação particular com a linguagem. Acompanhando Deleuze (1998), indagamos se não seria talvez esta relação essencial à linguagem, em "fluxo" de palavras, um discurso louco que desliza incessantemente sobre aquilo que remete sem jamais se deter.

Desse movimento, que não cessa, podem-se extrair consequências: o "nome próprio", pois o sendo singular, garante-se pela permanência de um "saber". Este saber é encarnado em "nomes gerais que designam paradas e repousos, substantivos e adjetivos, com os quais o próprio [o saber] conserva uma relação constante" (DELEUZE, 1998, p. 2). 
Então, o saber pode ser talvez isso que repousa nas palavras - quando o fluxo desatinado cessa, estabiliza. No sentido contrário, a perda do nome próprio pode desencadear o fluxo disparatado, fraturar a relação constante. Nesta situação tem-se, então, um "fluxo louco".

\section{OS NOMES PRÓPRIOS E O TRAÇO MNEMÔNICO DA HISTÓRIA: FREUd E BLEUler}

Os traços históricos - do imaginário da história falada ao documento epistolar até ao escrito teórico - vazam nos "pequenos grupos" institucionalizados. Tentarei recuperar "pelo menos um" destes traços históricos, aquele apontado pela conjunção dos nomes Bleuler-Freud.

Se desse modo a invenção freudiana capengou quando - após ser confrontada com as estratégias estruturalistas - encontrou-se com o "pensamento do acontecimento" é porque havia algo mais $(+)$. É porque a partir do campo do inconsciente tornou-se possível o engendramento de condições outras que ele impunha. Porque foi possível antever, vislumbrar novas possibilidades distintas daquelas que o Édipo permitia como "medida" - fixado como estava ao dispositivo da genealogia familiar. Aqui, reafirmamos a proposta de uma retomada inventiva do debate deleuze-guattariano com a psicanálise. Poderíamos dizer, então, que a direção psicanalítica faz aqui sua inflexão tomando o "pensamento do acontecimento" como ponto de bifurcação para a teoria do inconsciente. É do fundo de desmedida próprio do inconsciente que se trata, frente às "soluções" sempre sócio-históricas para o seu contorno, medida, tal como foi o saber edípico para a teoria das neuroses. Da neurose à psicose, temos, portanto, mais que dois capítulos de uma teoria clínica do processo de subjetivação e, sim, dois modelos do inconsciente que contrastam no trajeto pós-freudiano que se bifurca.

$\mathrm{Na}$ teoria geral das neuroses freudiana que compreendia como sua base o recalcamento (Verdrängung), este mecanismo etiopatogênico era o obstáculo a ser ultrapassado. Havia algo, alguma coisa que ainda resistia ao novo saber. Isso não passou despercebido aos freudianos mais inventivos - tornou-se, então, um capítulo apartado, ou seja, o capítulo das psicoses, da pura loucura ou da loucura pura, que fazia questão - insistia e perdurava.

Quer nos parecer que é isso que emerge que está impresso sob o título inconsciente, "esquizofrênico". História acidentada, complicada, que deserda um certo freudismo ao fazer implicar a esquizofrenia no campo social - desinvestimento libidinal da privacidade familiar.

A psicanálise freudiana foi refratária a clínica das psicoses. Entretanto, Lacan nos indicou a importância de não nos furtar ao enfrentamento das psicoses. O pensamento deleuze-guattariano vai nessa direção subvertendo-a. Considera a esquizofrenia como processo de produção de desejo e de máquinas desejantes produtoras, não correspondendo a nenhuma especificidade ou a uma entidade nosológica. Esses autores, muito pelo contrário, consideram-na como processo 
que excede todas as categorias ideais, formando um ciclo desejante como princípio imanente. Talvez, dizem, Freud não gostasse dos esquizofrênicos por sua resistência à edipianização.

\section{O Esquizo e as línguas ou a Fonética no PSicótico, PALAVRas DESPEDAÇADAS EM LETRAS E SEUS SONS: UM EXERCíCIO de Fonética}

O filósofo começou considerações clínicas sobre Wolfson dessa maneira:

[...] consideremos um [...] texto cuja beleza e densidade permanecem clínicas. Aquele que chama a si mesmo de doente ou esquizofrênico “estudante de línguas” experimenta a existência e a disjunção das duas séries da oralidade: é a dualidade coisas-palavras, consumações-expressões, objetos consumíveis - proposições exprimíveis [...] (DELEUZE, 1970, p. 5, grifo nosso).

Ao anotar "beleza e densidade", aspecto estético e "rigor lógico", nem por isso o texto se qualifica como literário ou de lógica. Pelo contrário, ele faz denotar a "fração clínica", o estatuto patológico da fala - "no texto" - que vem muito justamente ao feliz encontro da meditação do filósofo - neste momentum do pensamento deleuziano. Que ele a faça (a meditação) tendo como horizonte programático "desconstruir a Idéia platônica” - quer dizer do É para o E, do ser para a partícula "e" - é um estratagema lançado à cara de poderosos adversários. Assim, nada mais distante da Filosofia - mas não dos filósofos - do que um diagnóstico diferencial. Mas o que poderia ser isso? Como poderia haver uma "periodização" da filosofia que passasse por diretrizes diagnósticas, senão que de fato pelo menos um sintoma fosse suposto?

Ele, nosso filósofo, o dirá nessa afirmativa negativa (primeira frase) sobre as imagens do filósofo - e, não sem uma certa tonalidade de vaticínio

Não vamos comparar os filósofos e as doenças, mas há doenças propriamente filosóficas. O idealismo é a doença congênita da filosofia platônica e, com seu cortejo de ascensões e de quedas, a forma maníaco-depressiva da própria filosofia. A mania inspira e guia Platão. A dialética é a fuga das Idéias, a Ideenflucht; como Platão diz da Idéia, “ela foge ou ela perece...”. E mesmo na morte de Sócrates há algo de um suicídio depressivo (DELEUZE, 1998, p. 131).

Suspeitamos que o sintoma suposto seja a dialética. Tal como manejado pelo filósofo, a "fuga das ideias" - nos quadros maníacos - pode querer designar esterilidade à deriva, fluxo desvairado da excelência do Mesmo, palavras que nada dizem senão para dizerem o idêntico a si.

De resto fica que a diretriz diagnóstica - para o diagnóstico diferencial de esquizofrenia - exclui o quadro bi-polar: mania, depressão psicótica (a antiga psicose maníaco-depressiva). 
Essa habilidade diagnóstica é notável no filósofo. Mas em 1968 ele sabe das doenças que fatigam e exaurem, que tiram o ar. Ele as experimenta justo na caprichosa arquitetura fisiológica dos órgãos em que as próprias palavras se iniciam - ar do motor dos sons. Nosso filósofo padece. Como ignorá-lo ao se ler o pungente primeiro parágrafo de Espinosa Filosofia prática?

Por tê-lo vivido, Nietzsche percebeu em que consiste o mistério da vida de um filósofo. O filósofo se apropria de virtudes ascéticas - humildade, pobreza, castidade - para fazê-las servir a fins totalmente particulares, inusitados, na verdade muito pouco ascéticos. Ele faz delas a expressão de sua singularidade. Mas isso não significando para ele fins morais, nem tampouco meios religiosos para outra vida, mas antes os "efeitos" da própria filosofia. E isso porque para o filósofo não existe em absoluto outra vida. Humildade, pobreza, castidade tornam-se, assim, os efeitos de uma vida particularmente rica e superabundante, poderosa o suficiente para ter conquistado o pensamento e ter-se subordinado a qualquer outro instinto - isso a que Espinosa chama a Natureza: uma vida não mais vivenciada a partir da necessidade, em função dos meios e dos fins, mas a partir de uma produção, de uma produtividade, de uma potência, em função das causas e dos efeitos. Humildade, pobreza, castidade, eis a maneira própria de o filósofo ser um Grande Vivente, e de fazer de seu próprio corpo um templo para uma causa por demais orgulhosa, demasiado rica, demasiado sensual. De tal modo que, ao atacar o filósofo, sofremos a vergonha de atacar um invólucro modesto, pobre e casto; o que intensifica a raiva impotente, pois ele, o filósofo, não oferece nenhuma resistência, a despeito de padecer todos os golpes (DELEUZE, 2002, p. 9).

Nada impede que esse seja o portrait de um filósofo : além de um desejo, um voto. Creio que uma vida também pode causar, ser a causa de um outro filósofo. Desse envelope corporal pronto a se desfazer, a ruir, resta que lhe fica a potência de ter conquistado o pensamento. Tarefa em si mesma revolucionária. Exilado em sua própria língua, sua Tribo, Espinosa emerge - soberano - do trabalho de escritura de um discurso do Agir. Mostrando os passos necessários. Desenhando as formas das virtudes, pois as virtudes são refratárias ao seu ensino, elas se aprendem no exemplo do ato virtuoso.

\section{A mania platônica é bem pouco Estóica... ${ }^{1}$}

Desse modo, ao conferir à filosofia um quadro nosológico inteiro - forma maníaco-depressiva - trata-se antes de localizar e contrapor uma outra forma nosológica - dessa vez com a aposta de uma marca na qual as palavras, loucas, dizem. Enfim, pode-se pensar que o quadro descrito denota - tudo parece indicar - uma espécie de esterilidade. Nem a mania tampouco a melancolia - na letra do 
filósofo - estão aptas a produzirem algo novo senão circularidade tímica que é essa afetividade de litigiosa improdutividade. Então, tomar os comentários deleuzianos da história da filosofia como recusa da nosologia bipolar aponta para uma nova estratégia do pensamento - certamente, agora, muito menos "anti" - e, que se aproxima da palavra louca, em sua desmedida, esquizoanaliticamente, como o procedimento de colagem em relação com as torções exercidas pelo pensamento de Deleuze. Tais comentários resultam das alianças com pensadores, que instrumentalizam a afirmação de uma filosofia da diferença, levada a efeito por Deleuze como, por exemplo, os estóicos ao pensar a causalidade.

O estoicismo ao subverter a mania platônica de pensar a relação causal distingue duas espécies de coisas: os corpos-causas e os efeitos incorporais - acontecimentos. Só os corpos são causas-misturas, já os acontecimentos são incorporais (sentidos, efeitos, expressos) irredutíveis aos corpos e às Ideias altas platônicas. Trata-se da imagem dos estóicos como pensadores da superfície em contraste com o pensamento da altura e da profundidade do platonismo. Essa diferença entre o modo de pensar platônico que vingou no ocidente e, as avessas dessa corrente dominante, o que os estóicos contribuem para pensar o "cogito esquizo", oferece pistas para pensarmos uma clínica da esquizofrenia

\section{UM ESQUIZOFRÊNICO AMERICANO QUE ESCREVE EM FRANCÊS}

Em um dia de verão, 2 julho de 1970, o escritor francês Jean Ristat (1970, online) perguntou ao filósofo:

O autor desse livro, Louis Wolfson, se chama "o estudante de língua esquizofrênica", "o estudante de idioma demente". Creio que essas poucas expressões são suficientes para colocar o leitor do "Esquizo e as línguas" em uma situação de estranhamento ao mesmo tempo pela dor, o trágico e o humor que atravessam esse livro.

No plano do "estranhamento" - essa esquisita familiaridade - encontramo-nos no tema em que o filósofo deseja ou quer arrancar, extrair, essa parte da experiência humana que confina com "a dor" e "o trágico" e traduzi-la. Um esquizofrênico - um psicótico - pode nos mostrar isso quando "escreve", e ele é pródigo em fazê-lo. Desse modo, torna-se possível passar da "experiência inefável do estranhamento" à letra, da letra ao texto, do texto ao seu comentário e segue-se da crítica à clínica.

Continua Jean Ristat (1970, p. 1) seu admirável questionamento:

[...] Wolfson é americano e escreve em francês. Mas ele recusa sua língua materna e emprega um procedimento lingüístico do qual você diz no seu Prefácio, Gilles Deleuze, que ele apresenta analogias notáveis com o célebre procedimento - ele próprio esquizofrênico - do poeta Raymond Roussel. Analogia mas também diferença. E toda 
a questão me parece estar aí: Wolfson não escreve uma obra literária e, todavia, dizer isso nos autoriza considerar seu livro como uma obra de doente mental?

Talvez isso queira dizer ou poder-se-ia concluir, então, que - a partir do Raymond Roussel de M. Foucault e do Louis Wolfson de Deleuze - obra literária, literatura, é o "problema" de "escrever"? (DELEUZE, 1997). Quer dizer, a dimensão do problema se expõe em dois polos os "[...] belos livros estão escritos numa espécie de língua estrangeira" (DELEUZE, 1997, p. 8). Assim, a "obra de arte" e a "língua estrangeira".

Na polaridade língua estrangeira se pode sentir quão dessemelhante é o devir "obra de arte". A experiência da "língua estrangeira" comporta um grão de intensidade incomum, de mundos diferentes, da narrativa do fluxo do tempo em movimento.

A letra, a língua, a literalidade escrita do texto, a bela palavra, o "Prólogo" de uma só única lauda de Crítica e Clínica são tantos outros problemas. "[...] no antigo teatro grego, a primeira parte da tragédia, em forma de diálogo entre personagens ou monólogo, na qual se fazia a exposição do tema da tragédia" (DELEUZE, 2002, p. 9). ${ }^{2}$ E é nesse prodigioso Prólogo de Crítica e Clínica que o problema da literatura encontrou seu eco enigmático. "A literatura é saúde" (DELEUZE, 2002, p. 10). Mas, todavia essa proposição engendra, propõe, contém um "novo problema", muito além e distante do escopo deste artigo.

\section{Mas, aQui se trata do Pensamento de UM FILÓSOFo ${ }^{3}$}

Em seus livros, procurou a natureza do acontecimento, que é um conceito filosófico, o único capaz de destruir o verbo ser e o atributo. Nenhum problema que o filósofo possa se pronunciar sobre uma psicose - esquizofrenia. Mas que ele o faça convocando o antropólogo americano Gregory Bateson e a Ciência Comportamental, dialogando com o médico-psiquiatra Jacques Lacan e propondo uma outra coisa torna-se, então, um Problema, e com dimensões bastante significativas. Seria óbvio e trivial se perguntar por que e a que título um filósofo se pronuncia com tanta propriedade e pertinência clínica sobre uma enfermidade? ${ }^{4}$ É que Gilles Deleuze (1998), a partir de Bleuler (1950), forçou, com todas as letras filosóficas, impor o Delírio co-presente na Schizophrenia como um discurso que se declama e declina como histórico-mundial.

\section{Notas}

\footnotetext{
${ }^{1}$ A sobrevivência do termo mania denotando quer seja um ato obsessivo, ação forçada, mímica corporal desencontrada e etc., também pode ser a ousadia de interrogar a "mania platônica" em seu próprio terreno.

${ }^{2}$ Houaiss, Dicionário, verbete prólogo. Na tradução de Pelbart o Prólogo de Crítica e Clínica (DELEUZE, 2002, p. 9-10) com 3 frases é de uma intensidade orquestral, jorrando sonoridades em mil tons: "Arrasta a língua para fora de seus sulcos costumeiros, leva-a a delirar".

${ }^{3}$ Se a teoria da neurose interpelou o Saber a partir do acontecimento o Inconsciente ,então um filósofo, pode muito bem se aventurar na saga freudiana.

${ }^{4}$ Sobre o estatuto de doença ver: DELEUZE (2002).
} 


\section{REFERÊNCIAS}

BLEULER, E. Dementia prcecox or the group of schizophrenias. New York: International Universities Press; 1950.

DELEUZE, G. Préface à l'ouvrage de Louis Wolfson: le schizo et les langues. In: OLFSON, L. Le schizo et les langues. Paris: Gallimard, 1970. p. 5-11.

DELEUZE, G. Lógica do sentido. São Paulo: Perspectiva, 1998.

DELEUZE, G. Espinosa: filosofia prática. São Paulo: Escuta, 2002.

DELEUZE, G. Crítica e clínica. Tradução de Peter Pal Pélbart. São Paulo: Editora 34, 1997.

PRÓlogO. In: Dicionário Houaiss da Língua Portuguesa. Rio de Janeiro: Objetiva, 2001.

RISTAT, J. Entretien avec Gilles Deleuze. L'Humanité (1970), Saint-Denis, 28 fev. 2006. Disponível em: <www.humanite.fr/2006-02-28 Cultures JeanRistat-entretien-avec-Gilles-Deleuze-France-Culture-2>. Acesso em: 12 jul. 2008.

Recebido em: setembro de 2009

Aceito em: junho de 2010 
